\section{Mechanical Philosophy: Reductionism and Foundationalism}

\section{Tzuchien Tho}

Department of Philosophy, University of Bristol, Bristol, UK

\section{Related Topics}

Mechanical philosophy $\cdot$ Reductionism ·

Foundationalism - Demonstrative knowledge ·

Atomism · Experimental philosophy ·

Rationalism $\cdot$ Empiricism $\cdot$ Scepticism

(Skepticism) $\cdot$ Laws of motion

\section{Introduction}

Reductionism, the mode of natural explanation which reduces complex phenomena (including mental phenomena) to simple and epistemically or ontological brute entities or sensibles, is not an exclusively modern trend. All pre-Socratic philosophers are known through their various proposals for a reductionist ontology (i.e., water, indivisibles, four fundamental elements, etc.). Reductionism in modern philosophy is often understood as the sine qua non of mechanical philosophy. Among the various sects of this general theoretical tendency in the early modern period however, to what a reductionism would reduce was a matter of much debate. Yet some of the common motivation among these tendencies can be identified with the overall rejection of causes in nature other than material and efficient causes. Hence reductionism should be understood as a strategy of explanation rather than necessitating particular ontological commitments.

While reduction to a brute entity or a series of fundamental elements can be traced back to the pre-Socratics, foundationalism, as we understand it, is more exclusively associated with the emergence of modern philosophy. While reductionism is ancient, foundationalism, on the other hand, is more exclusively associated with the emergence of modern philosophy. Although the term is not an actor's category, thinkers such as Descartes sought to overcome the threat of (self-imposed) hyperbolic skepticism through the establishment of foundational knowledge. However, earlier theories of knowledge such as what we find in the Aristotelian-scholastic tradition could also be called "foundationalist" in the sense that it sets up a hierarchy for the degrees of knowledge, where we move from less certain ways of knowing and move "up" to apodictic knowledge (demonstrative) which achieves the highest and most certain form. We find in early modern foundationalist thinking, borrowing from the image of Euclidian demonstration, an inverted hierarchy that moves from the ground of a small number of certain knowledge to more complex forms. The key difference here is that Aristotelian knowledge works "up" toward certainty where Cartesianism is grounded "down" in certainty. Of course, Descartes and Aristotle share a 
common recognition of geometrical demonstration as apodictic. However, Descartes grounds knowledge on the clearness and distinctness of ideas, of which geometrical certainty is a paradigmatic case. Hence complex forms of knowledge are certain if they are rooted in the solid foundation of fundamental axiom-like clear and distinct ideas. Hence, while reductionism was a strategy of explanation, foundationalism was a method of knowledge.

This entry will address the unique confluence of reductionism and foundationalism in the mechanical philosophy of the early modern period. The result of this confluence of a mode of explanation with a method of knowledge is that only reduction to mechanical principles constitutes well-founded knowledge. However some thinkers within the tradition also sought to undo the restrictive implications of this confluence without rejecting the first fruits of the mechanistic program.

\section{The Internal Problems of Reductionist Explanation in Mechanical Philosophy}

We have indicated above that reductionism and foundationalism are different aspects at work in early modern natural philosophy. In the case of Descartes, these are distinct but mutually supporting projects: the reduction of the natural world to its ontological basis in extended substance (res extensa) is in deep sympathy with the foundation of knowledge in clear and distinct ideas. Since geometry is a priori and based on clear and distinct ideas, the reduction of physical reality to instantiated geometrical relations allows for a convenient convergence of reductionism and foundationalist epistemology. Though Cartesian matter (res extensa) is inert, the laws of material interactions and transformation are sustained by God's decree, concurrence, and conservation (AT VIII, 61; CSM I, 240; Arthur 2007). The official view here is that there is simply nothing other than geometrical truths to be known about the nature of extended beings. (This is complicated by the ambiguous account of the laws of nature in the Principia Philosophiae which appear to provide conditions beyond mere geometrical relationships.) However, for a broad number of key mechanists like Gassendi and Boyle, this convergence does not follow. For a standard set of canonical thinkers in the tradition, it is ontological reductionism rather than epistemic foundationalism that most characterizes this project of mechanical philosophy.

The standard identification of mechanical philosophy with materialism and atomism (understood by some scholars as one and the same for the pre-modern and early modern period) is not entirely mistaken. The term "mechanical philosophy" was first used by H. More and R. Boyle (Hattab 2011; Anstey 2000). While Boyle did not make any ultimate commitment to indivisibles, the project of "mechanical or corpuscular philosophy" was rooted in the use of atomistic hypotheses as a means of designating the proper domain of natural explanation even when the authors were not fully committed to indivisibles (Pyle 1995; Boyle 1999, I, 474). (The relation between a hypothetical commitment to atomism and the legitimacy of mechanical philosophy in Boyle has been litigated between A. Pyle, A. Clericuzio, P. Anstey, and A. Chalmers in a series of corresponding articles. See Anstey 2002; Chalmers 2002; Clericuzio 1990, 2000; Pyle 2002, 2018.) However, if we expand the term "mechanical philosophy" to a wider set of figures to include the Italian contingent featuring Guidobaldo del Monte, Galileo, and the Galilean school, the atomistic doctrine cannot be considered a necessary aspect of the reductionist position (Garber 2002). "Mechanics" in this tradition prescribes a form of explanation that reduces to the five (or six) classical machines (Guidobaldo 1577, cited in Garber 2002).

Understanding God as the divine artificer of a complex machine (the world) was not uncommon for all sects of the mechanical tradition. However, this view does not have to imply anything about the ultimate constituents of reality. (The term "mechanistic philosophy" may now seem a bit nominalistic between those who self-professed and those whom later historians called "mechanistic." We make the distinction while tarrying with the ambiguity. See Boudri 2002.) Insofar as 
reductionist explanation does not have to commit to entities at the irreducible level of reality, the reduction to mechanical aggregates can serve as the models for the explanation of phenomena. Nonetheless, this view does incur the ultimate theoretical burden of implying that motion must be an extramundane input to nature. Like any machine, what is arranged is bodies. This does not imply that the machine is operative through some internal principle as atomists like Gassendi held or according to the Leibnizian theory of immanent "living force." The Aristotelian tradition affirmed natural motions and places due to causes (final and formal) that mechanists saw as occult and illegitimate. The actuality of an immanent principle of motion in nature remained a debate in this domain well into the eighteenth century. The use of reductionistic mechanism in the life sciences where immanent organic growth (the preeminent form of Aristotelian motion) was seemingly irreducible also remained an abiding difficulty (Des Chene 2001; Hutchins 2015; Baldassarri 2019). Nonetheless Descartes' affirmation of reductionism and foundationalism was consistent on this account. Matter was inert and motion only exists through an external mover (God).

Hence while materialism and corpuscularianism can be legitimately understood as a key doctrine among the mechanical philosophers, it is not a necessary feature of this approach to explanation (Dijksterhuis 1969). Reductionism does not have to be either complete or go "all the way" to the ultimate metaphysical constituents of reality but only to the functional aspects of nature, analogous to machines of art, responsible for its basic operation.

For the atomists among the mechanistic philosophers, reductionist explanation was a reduction to atoms or corpuscles. This view constitutes a mainstream of mechanistic philosophy that reduces physical explanation to fundamental entities. In its most fundamental aspect, the spatiality of bodies is accounted for by the spatiality of their fundamental constituents. This aspect is continuous with historical atomism from classical sources. However, the explanation of physical properties requires further properties of observable phenomena outside of spatial ones. While matters like spatial position and locomotion (change in place) can be geometrically explained through fundamental constituents or parts mechanically arranged, properties like heat, color, and even weight (or mass) require further elaboration. This was a problem with little straightforward agreement among the mechanical philosophers.

Prominent atomists like Gassendi and Boyle, though differing in their commitment to the view, did appeal to features of atoms that should be understood as qualities or principles independent of their indivisibility. Most intuitively, color is interpreted as a sensory effect of the texture of indivisibles. More problematically, the property of heat was speculated to be reducible to the "calorific" or "frigorific" atoms which may reside in particular bodies (Gassendi 1658, I, 394-401; Boyle 1999, IV, 380-381). (As ever, Boyle is skeptical of this possibility but seriously maintains the hypothesis for experimental purposes. See Pyle 2018.) The danger here is that this view reintroduces the Aristotelian appeal to principles and essences that the reduction to atoms was supposed to avoid. Of course we cannot expect historical authors to have "purified" their writing to the retrospective standards of the historian of thought. This issue however does identify a recurring problem of this atomistic version of mechanical reductionism. With generosity, Boyle does provide a suitable answer to this question by distinguishing between the universal matter of atoms and their transmutation into various forms. Appealing to the tradition of alchemy, he argues that orderly transmutations of "one common matter" can give rise to the variation of principles inherent in bodies as composites (Boyle 1999, III, 13). This view is not entirely free from the elemental principles of Aristotelianism but does provide enough to justify the plausibility of universal reduction.

The irreducibility of qualitative principles among the atomists has a counterpart among the nonatomists. Thinkers like Descartes and Hobbes held a sister concept to atomism. With selfdescribed corpuscularianism, they rejected the explicit doctrines of atomism and traditional accounts of the void and the indivisible entity. 
From them, nature was reducible to explanations based on size, shape, and motion. However, this reduction did not require the further ontological basis to ultimate indivisibles. In relation to the former problem, Descartes was explicitly clear that qualitative properties like heat and moisture were due only to the motion of bodies (AT XI, 25-26, CSM I 89; AT XI 33, CSM 191). This reliance on a minimalist ontology also involved some gaps of explanation. What was lacking, as the later Leibniz and Newton would point out, is the principle of resistance in the interaction between bodies. In the case of Descartes and Hobbes, the reduction of physical phenomena to size, shape, and motion implies that the phenomenon of resistance and elasticity of bodies can only be accounted for by externally imposed principles of interaction (such as the laws of collision in Principia Philosophiae and its similar but alternative version in De Corpore). Hence while Descartes and Hobbes explicitly disagreed on the laws of motion (and its definition), they agreed on the rejection of any inherent property in matter irreducible to external spatial relations (i.e., geometrical properties). Resistance and elasticity do not emerge from the inherent properties of bodies themselves. This provided much fodder for later physical theorists of collision (Murray et al. 2011). (Later critics of Descartes on elasticity include C. Huygens, G.W. Leibniz, I. Newton, E. du Châtelet, etc.) Descartes' fundamental errors in his laws of collision provide the occasion for the disputation of whether an internal force of resistance (a proto-inertia concept) was necessary for physics (Gabbey 1971; Bernstein 1981). However, the empirical errors of Descartes' laws were not logically due to the reductionistic view itself. Certainly, a more accurate account of inertial force could have been defended without the adoption of the metaphysics of "inherence" (e.g., the modern theory of inertial mass). Nonetheless, later thinkers such as Leibniz and Newton argued that some internal force of resistance (vis insita) or elasticity must be understood as a key participant in physical phenomena such as collision and (for Newton) attraction.

\section{The Synthesis of Reductionism and Foundationalism}

As we have identified above, many modern natural philosophers embraced reductionism as the legitimate means to provide explanation for physical phenomena. By appealing to earlier traditions, atomists sought to reduce natural explanation to the properties and behavior of indivisibles. Nonatomists sought to reduce natural explanation to the size, shape, and motion of bodies whether these reduce to indivisibles, some other kind of thing, or whether they reduce at all. As we have seen, a reductionist approach to explanation does not have to go "all the way" to primary constituents. Appealing to Guidobaldo Del Monte, the reduction to composed machines may be a more sensible way to identify what was so "mechanical" about the so-called mechanists (Guidobaldo 1577). This characterization opens up an important question. If the nonatomists did not appeal to the fundamental entity, what grants the certainty of reduction? In thinkers like Descartes, the reductionist strategy was the consequence of a foundationalist theory of ideas. We shall examine this point here.

Among the mechanical philosophers, we find two main themes in the theory of ideas (or theory of knowledge). The first is the Baconian-inspired experimental method based on induction and the dynamic fallibilist interplay of empirical observation and rational taxonomy. The second is the Cartesian method, often called "rationalist," that roots knowledge on the a priori clearness and distinctness of ideas. Of course these two traditions are not exclusive; Descartes himself claims a debt to Bacon as do other canonical "rationalists" such as Leibniz. Conversely the Lockean program of the theory of ideas is also deeply foundationalist insofar as it is rooted in the basis of sense certainty eschewing the a priori basis of clearness and distinctness. Nonetheless, as we move to the later part of the modern period, these two traditions move further apart. In Leibniz's polemical disputation of Locke's $A n$ Essay Concerning Human Understanding, we see the maturation of one corner of this debate regarding the plausibility of "innate ideas," a 
parting of ways that becomes rigid by the time of Wolff and Kant. Nonetheless, it is important to highlight the variation in the bottom-up foundationalism that characterizes modern philosophy.

For the Descartes of the Meditations, the irreducibility of mind to matter grants matter a clear and distinct nature as res extensa. The reduction of physical qualities to the clear and distinct res extensa, without any further commitment to atoms or other substantial qualities, is grounded in this epistemic criterion. In the Principia Philosophiae, Descartes provides a more positive account of the substantial nature of res extensa. Although the logical development of the text implies that neither mind nor matter could stand independently of the divine, material substance is identifiable as a kind of instantiated geometry, determined only by spatial qualities. Further properties of impenetrability, surface properties, elasticity, and the like are relegated to modal secondary features emergent from size, shape, and motion. From this position, we can see that reductionism is implied in Descartes' theory of ideas (the criterion of certainty) rather than having an independent motivation.

It could be conversely argued that foundationalism does not have to include any reduction. This is most apparent in the later transcendental philosophers of the German tradition. However we can already see this view at work in Locke. Locke's writings are shot through with Baconian experimentalism. Yet, with explicit Cartesian inspiration, Locke's epistemology was systematically empiricist (a rejection of innate ideas), based on simple and complex ideas produced in the mind by sensory experience. The system is complex but well-known. For Locke, the foundation of knowledge on the certainty of simple ideas does not have to imply either atomism or any other ontological reduction (Locke Essay IV, 3, 11). The program of ontological reduction in natural explanation is entertained by Locke but not necessitated by the foundational chain of mental association that connects simple to complex ideas. Explanation is, in the tradition of Locke, epistemic in character and, hence, in line with the fallibilist experimentalist tradition. Hence even as Locke distinguishes primary and secondary qualities in perception (the epistemic chain), the real essences of things are, as a practical matter, ultimately inaccessible (Locke Essay III, 6, 2).

\section{The Independence of Reductionism and Foundationalism}

In the work of Leibniz, we find another kind of response to this issue of reductionism, foundationalism, and their relation. The most important thing to highlight here is the relativization of levels of explanation that we find in his work. In the strict interpretation of mechanical philosophy, a physical phenomenon has to be merely reduced to its functional parts interpreted "mechanically" rather than ultimately. (Needless to say, the adult Leibniz never adopted atomism even though he claims to have been an adherent in his early youth. GP III 620.) The natural philosophy of Leibniz follows in this tradition, affirming broadly materialistic explanations based solely on aggregated bodies and efficient causality (Leibniz, Specimen Dynamicum, GM IV, 234-253, AG 117-138). However, Leibniz also affirmed that these accounts are embedded in a broader family of causal relations, including teleological causation that was eschewed by his contemporaries. His famous assertion that it is living force (measured by $\mathrm{mv}^{\wedge} 2$ ) that is universally conserved in nature (instead of merely the conservation of the quantity of motion mv) is based on what he argued to be "perceptible by the mind alone" beyond mere empirical observation or reduction to external geometrical relations (GM VI 241, AG 125). The contemporary reader may rightfully wonder why the conservation of energy (for which living force qua $m v^{\wedge} 2$ is an archaic form) could be understood as metaphysically beyond other features of observable physical properties. There are many subtleties here, but Leibniz interprets living force, within the framework of seventeenthcentury physics, as incompatible with any theory rooted in the inertness of extended substance. Hence Leibniz accepts the rational legitimacy of 
explanation through reduction but rejects its fundamentality.

Leibniz introduces a relativization of explanatory frameworks. On one hand, material entities and efficient causation are sufficient to provide a mathematical account of corporeal motion. On another hand, the theory of living forces provides an additional layer by identifying the conserved quantity in corporeal motion. This additional aspect, for Leibniz, indicates not only that there is an inherent aspect of physical bodies unrecognized by the reductive mechanistic account but also that efficient causality is insufficient to capture the completeness of the causes pertinent to locomotion.

Like Locke, Leibniz's physical theory presents a foundationalism without reductionism. They are sympathetic in the project of foundational knowledge of nature while relativizing (or instrumentalizing) the entity for which this foundation relies. While Locke hypothesizes atomism but is uncommitted to it, Leibniz rejects atomism on the basis of sufficient reason (G VII 378, AG 332). The result here is that the confluence of reduction and foundation in mechanistic philosophy also gave rise to a theoretical independence between the reductionist project and the foundationalist one in the late seventeenth century.

\section{Cross-References}

\author{
> Boyle's Mechanical Philosophy \\ - Corpuscularianism \\ $\checkmark$ Descartes \\ - Descartes' Mechanical Philosophy \\ - Gassendi, Pierre \\ - Gravity as a Property of Matter \\ - Hobbes on First Philosophy and Natural \\ Philosophy \\ - Huygens, Christiaan \\ $\checkmark$ Life, Mechanization of \\ - Light, Mechanization of \\ - Locke and Mechanism \\ - Magnetism (Mechanical) \\ - Mechanical Philosophies \\ - Mechanical Philosophy: an Introduction
}

- Mechanical Philosophy: Mechanics

- Mechanical Work

- Mechanism and Chemistry in Early Modern Natural Philosophy

- Mechanism: 18th-Century German Philosophy

Newton and Leibniz

\section{References}

Anstey P (2000) The philosophy of Robert Boyle. Routledge, London/New York

Anstey P (2002) Robert Boyle and the heuristic value of mechanism. Stud Hist Phil Sci 33:161-174

Arthur R (2007) Beeckman, Descartes and the force of motion. J Hist Philos 45(1):1-28

Baldassarri F (2019) The mechanical life of plants: Descartes on botany. Br J Hist Sci 52(1):41-63. https://doi. org/10.1017/S000708741800095X

Bernstein H (1981) Passivity and inertia in Leibniz's dynamics. Studia Leibnitiana 13:97-113

Boudri JC (2002) What was mechanical about mechanics: the concept of force between metaphysics and mechanics from Newton to Lagrange. Springer, Dordrecht

Boyle R (1999-2000) In: Hunter MCW, Davis EB (eds) The works of Robert Boyle, vol 14. Pickering \& Chatto, London

Chalmers A (2002) Experiment versus mechanical philosophy in the work of Robert Boyle: a reply to Anstey and Pyle. Stud Hist Philos Sci 33:187-193

Clericuzio A (1990) A redefinition of Boyle's chemistry and corpuscular philosophy. Ann Sci 47:561-589

Clericuzio A (2000) Elements, principles and corpuscles: a study of atomism and chemistry in the seventeenth century. Kluwer, Dordrecht

Del Guidobaldo M (1577) Mechanicorum liber. Apud Hieronymum Concordiam, Pisa

Des Chene D (2001) Spirits and clocks. Machine and organism in Descartes. Cornell University Press, Cornell

Descartes R (1984, 1985, 1991) The philosophical writings of Descartes. 3 Volumes. Cottingham J, Stoothoff R, Murdoch D (trans.), and v. III, Cottingham J, Stoothoff R, Murdoch D, Kenny A (trans). Cambridge University Press, Cambridge (Cited by the abbreviation CSM or CSMK then volume number and page number)

Descartes R (1996) Euvres de Descartes. 11 Volumes. Adam Ch, Tannery P (eds). J. Vrin, Paris (Cited by the abbreviation AT then volume number and page number)

Dijksterhius EJ (1969) The mechanization of the world picture. Oxford University Press, Oxford

Gabbey A (1971) Force and inertia in seventeenth-century dynamics. Stud Hist Philos Sci Part A 2(1):1-67

Garber D (2002) Descartes, mechanics, and the mechanical philosophy. Midwest Stud Philos 26(1):185-204 
Gassendi P (1658) Petri Gassendi Opera Omnia. 6 Vols. Sumptibus Laurentii Anisson, \& Ioan. Bapt. Devenet, Lyon

Hattab H (2011) The mechanical philosophy. In: Clarke DM, Wilson C (eds) The Oxford handbook of philosophy in early modern Europe. Oxford University Press, Oxford, pp 71-95. https://doi.org/10.1093/oxfordhb/ 9780199556137.003.0005

Hutchins BR (2015) Descartes, corpuscles and reductionism: mechanism and Systems in Descartes' physiology. Philos Q 65(261):669-689

Murray G, Harper W, Wilson C (2011) Huygens, wren, Wallis, and Newton on rules of impact and reflection.
In: Jalobeanu D, Anstey PR (eds) Vanishing matter and the Laws of motion. Routledge, New York, pp 153-191

Pyle A (1995) Atomism and its critics: from Democritus to Newton. Thoemmes Press, Bristol

Pyle A (2002) Boyle on science and the mechanical philosophy: a reply to Chalmers. Stud Hist Phil Sci 33:175-190

Pyle A (2018) The theory of matter. In: Kaufman D (ed) The Routledge companion to seventeenth century philosophy. Routledge, London/New York, pp 410-446 